\title{
¿Y SI GAUDÍ HUBIERA IDO A NUEVA YORK? UNA FICCIÓN CONSTRUCTIVA
}

\author{
(AND WHAT IF GAUDÍ HAD VISITED NEW YORK? CONSTRUCTION-FICTION)
}

\author{
José Luis González Moreno-Navarro \\ Dr. Arquitecto. Catedrático de Construcción Arquitectónica en la Escuela Técnica Superior de Arquitectura de Barcelona. Universidad \\ Politécnica de Cataluña
}

Fecha de recepción: 2-III-05

ESPAÑA

\begin{abstract}
RESUMEN
El autor adopta el método de la ficción para poner de manifiesto contradicciones que se mantienen debido a la desquiciada mitomanía con la que se abordan muchos de los estudios que se realizan sobre la obra, construida o no, de Antoni Gaudi que impiden una visión serenamente crítica de su labor arquitectónica. El caso central que se aborda es el del hipotético hotel que debía construir en Nueva York, organizándosele un viaje a Gaudí a la ciudad de los rascacielos, lo que permite comparar su supuesta idea básica con la realidad de lo que entonces se hacía allí. Aprovechando esa estancia se le lleva a visitar la obra que Rafael Guastavino habia hecho en St. John the Divine lo que permite revisar críticamente algunas de la teorias del arquitecto catalán que, a pesar de todo, se siguen considerando correctas por parte de autores actuales de clara tendencia mitómana.
\end{abstract}

\section{SUMMARY}

The author adopts fiction-writing methods to reveal the contradictions in the mindless hero-worship underlying many of the studies conducted on Antoni Gaudi's oeuvre, not all of which were ever built: contradictions that hamper a serenely critical view of his architectural endeavour. The article centres on a hypothetical hotel that he might have built in New York, with the author embarking Gaudi on an imaginary trip to the skyscraper city to enable him to compare his presumed basic idea with the reality he would have encountered on his arrival. On the occasion of this fictional stay, Gaudi would have visited Rafael Gusatavino's design for St John the Divine, an episode that the author uses to critically review certain of the Catalonian architect's theories, still regarded to be correct today by a number of authors with clearly idolatrous leanings.

\section{EL MISTERIO DE UN ENCARGO}

Una de las incógnitas más inquietantes que nos ha dejado el ya lejano año 2002 es si fue Gaudí el autor de unos croquis que daban respuesta al encargo de un hotel en Nueva York por parte de unos señores americanos que le visitaron en 1908.

Este artículo se basa en el supuesto de que así hubiera sido y que, como consecuencia de ello, hubiera decidido viajar allí, por ejemplo, a mediados de 1909.

Su objetivo no es deleitarnos con una simple ficción novelesca sino de, por medio de esa suposición, ensayar otra manera de ejercitar nuestra capacidad de raciocinio sobre la construcción histórica de manera festiva (que no falta de rigor) y, quizá, algo más efectiva que un serio artículo convencional. Es por ese doble motivo por lo que en el título aparece el adjetivo constructiva, es decir, es una ficción sobre construcción y es muy provechosa o útil, o así lo quiero creer.
Si se repasa la prensa diaria de mediados de enero de 2003 se comprueba el interés suscitado por la presentación en Nueva York, con la intención de competir en la ocupación de la zona cero, de una recreación virtual de un proyecto de hotel de $360 \mathrm{~m}$ de altura atribuido a Gaudí. La certificación de la autoría ya había sido avalada nada menos que por el director de la Real Cátedra Gaudí, el cual ya había incluido, en su magno texto sobre la obra gaudiniana (1), la memoria completa en la que el hijo de un colaborador de Gaudí hacía pública, a mediados de los años cincuenta, un hecho desconocido por todos los biógrafos del arquitecto: la visita que le habían hecho a Gaudí unos neoyorquinos para encargarle el "macrohotel". La memoria iba acompañada de unos dibujos, unos, atribuidos a Gaudí y otros, realizados a partir de ellos.

Todo ello es bien conocido y, además de en el texto ya citado, se pueden encontrar más datos en otra publicación surgida en la vorágine del 2002 (2). Mi opinión personal, expresada de manera resumida, también apareció escrita (3). Estas líneas pretenden volver sobre ella de manera algo 


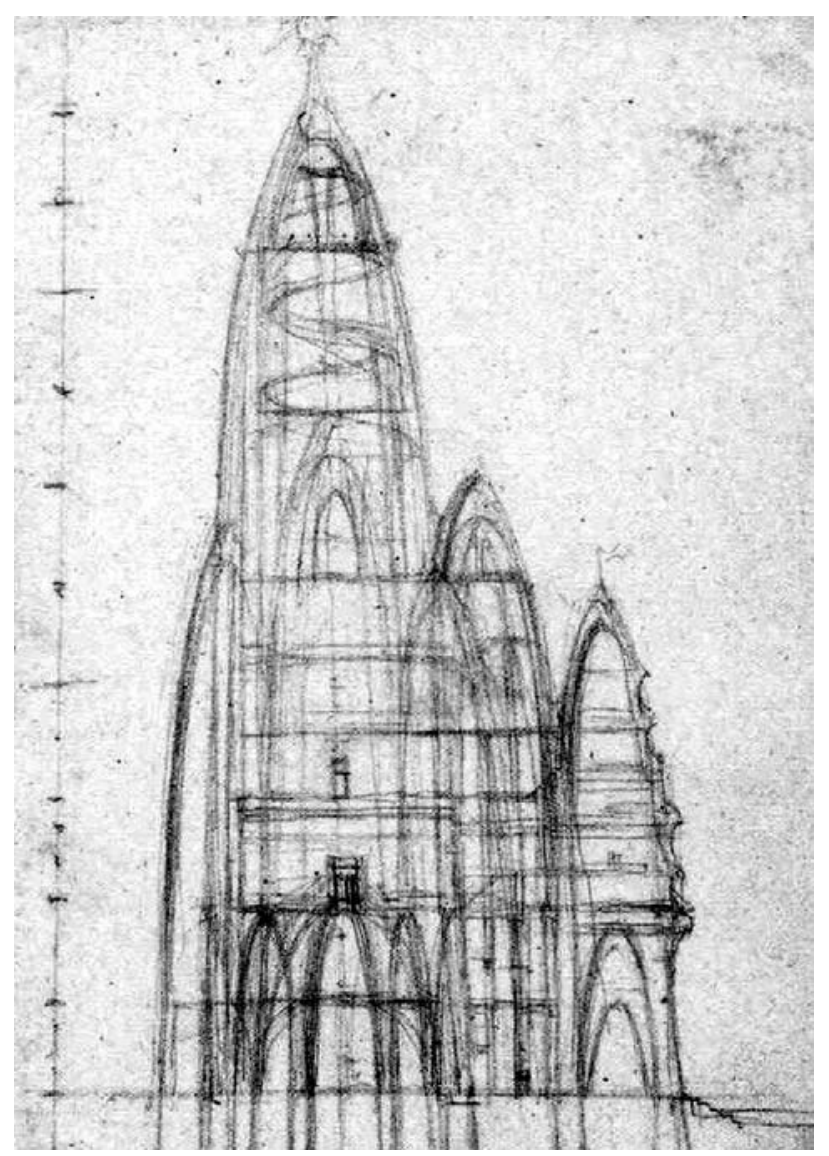

Figura 1.- Reproducción de uno de los croquis atribuibles a Gaudí.

más extensa, a la vista de la favorable acogida que tuvo mi conferencia sobre todo ello impartida en el Instituto Eduardo Torroja (4).

\section{EL CROQUIS DEL HOTEL}

Una simple mirada a uno de los croquis atribuibles a Gaudí (Fig. 1) permite deducir que el edificio estaba concebido bajo los mismos criterios que el arquitecto estaba aplicando en aquellos momentos al diseño de las torres de la $\mathrm{Sa}-$ grada Familia y las de la iglesia de la Colonia Güell. El esquema es sencillo y conocido, pero no por ello ocioso volverlo a repetir: si se invierte $180^{\circ}$ la forma adoptada por una cadena sujeta por sus dos extremos, es decir la catenaria, obtenemos una figura que si se adopta como directriz de un arco de obra de fábrica de piedra o ladrillo en su interior se consigue un perfecto reparto de los esfuerzos de compresión y la exclusión de cualquiera de tracción, es decir lo que también se denomina un arco equilibrado. El mismo criterio se puede aplicar a una cúpula de revolución generada por el giro de dicho arco alrededor de su eje vertical.

Jean Rondelet ya explicó, a principios del siglo XIX, el uso que él había hecho del método en el diseño de la cúpula intermedia de las tres de la iglesia de Santa Genoveva de París (Fig. 2) (5). Gaudí lo repitió extremando el punto

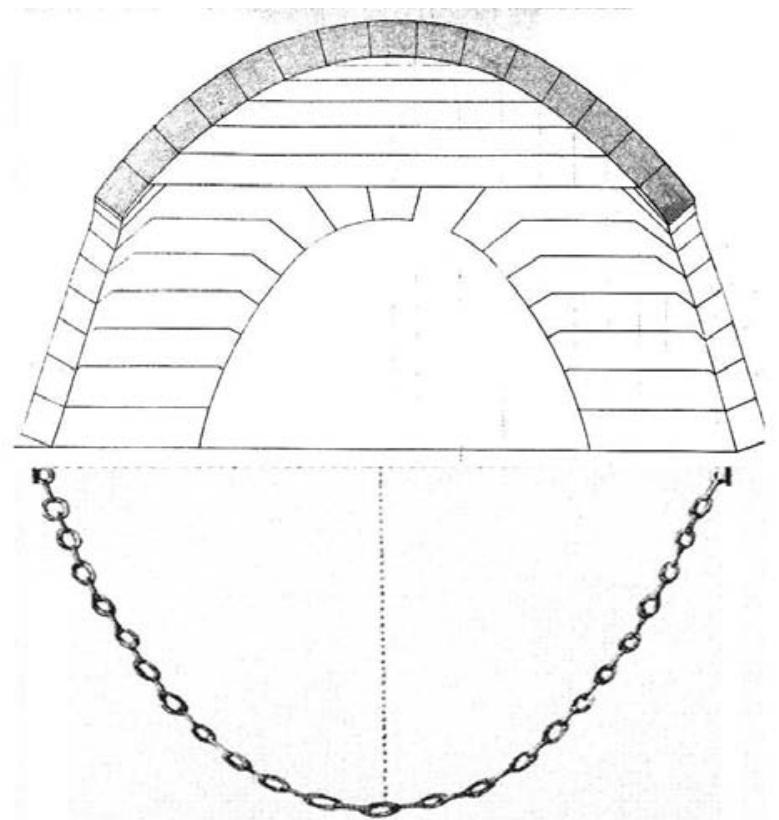

Figura 2.- Reproducción simplificada de los dibujos del tratado de Rondelet: abajo la cadena colgante que configura una catenaria y arriba una versión simplificada de la bóveda de santa Genoveva.

de las cúpulas hasta conseguir sus esbeltas torres que se podían construir en obra de fábrica sin temer ningún efecto adverso. Hasta tal punto estaba orgulloso de su método que aleccionó a su discípulo, Jeroni Martorell para que, en una hipotética discusión con los arquitectos franceses, en su visita a París, con ocasión de la exposición organizada por Güell, ofreciera ese perfil de sus torres como demostración de una superación (exclusivamente formal, añado yo) de la torres "telescópicas" de la edad media (6).

El argumento de la forma anticatenárica es, incluso, el que aporta Bassegoda para garantizar su autoría. Y si ésa es la forma del perfil, también es razonable suponer que la estructura del hotel habría de ser de obra de fábrica, de piedras o ladrillos tomados con mortero, única estructura para la cual tiene sentido esa forma.

Ahora bien, una cosa es una cúpula o torre vacía en su interior, como lo son estructuralmente las de la Sagrada Familia, y otra cosa es un hotel en el que, en su gran altura, se disponen decenas de elementos horizontales que dan soporte a los pisos de habitaciones, salas, etc., tal como se puede observar en el citado croquis.

Si repasamos las obras de Gaudí, el único caso en el que se presenta un elemento similar es el nivel soportado por arcos que separa las dos capillas superpuestas de la Colo- 


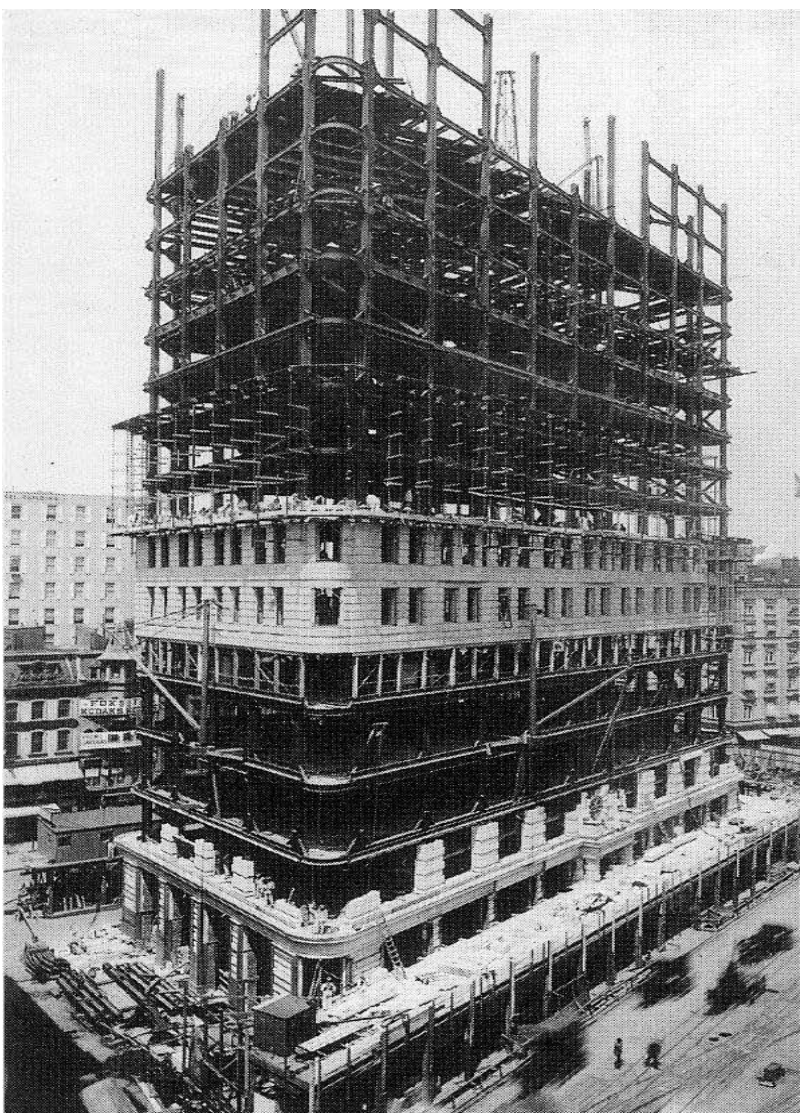

Figura 3.- El Flatiron Building en construcción, obviamente, con un entramado de perfiles de acero.

nia Güell. En este caso, el perfil general no es el de una catenaria sino el determinado por los empujes de aquellos arcos que inclinan la pared exterior cuanto más cercana está a su base.

En el caso del hotel nada de ello se advierte sino que el perfil se hace más vertical cuanto más cercano se encuentra al suelo. Y eso sólo se podría conseguir evitando los empujes laterales de los arcos soportes de los diferentes niveles, sustituyéndolos por otros elementos como jácenas

y vigas. Pero entonces el perfil lógico no sería el de la catenaria sino otro, determinado por las cargas verticales de los elementos horizontales. Parece evidente que hay algo que no cuadra.

\section{GAUDÍ SE VA A NUEVA YORK}

Quizá estaba en todo ello Gaudí cuando pudo haber aceptado la invitación de sus potentados clientes para ir a Nueva York, supongamos alrededor de 1909.

De entrada, es difícil, por lo menos para mí, imaginarme a Gaudí en un barco durante varios días, pero este esfuerzo de imaginación nos llevaría por otros derroteros más próximos a una narración novelada no buscada por ahora. Supongámoslo ya en la ciudad, precisamente, de los rascacielos. Sin duda, además de inspeccionar el hipotético lu-

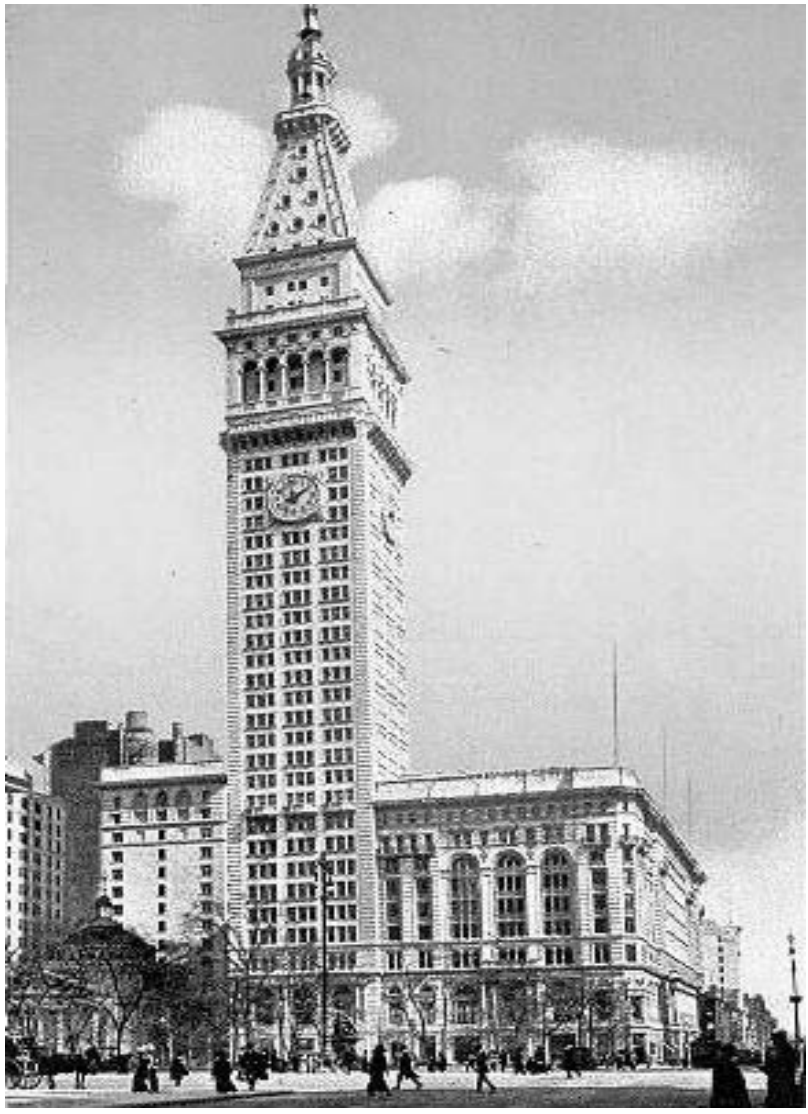

Figura 4.- El Metropolitan Life Insurance Tower finalizado en 1909.

gar para su proyecto, se interesaría por los edificios similares recientemente construidos.

Y se encontraría, entre otros menos famosos, con el Flatiron Building (Fig 3) y, sobre todo, con el recién terminado rascacielos "veneciano" Metropolitan Life Insurance Tower, en aquel momento el edificio más alto del mundo, con sus 213 m (Fig. 4). En una probable conversación con el arquitecto que lo proyectó, Napoleón Lebrun, hubiera profundizado en los problemas planteados por una construcción de tal altura y de las soluciones que ya se estaban ensayando con éxito desde hacía unos veinte años en su ciudad y en Chicago, de lo que nada había comparable, no sólo en Barcelona sino en toda Europa. Cuesta creer que Gaudí se enterara por primera vez que la solución ya ensayada era la estructura porticada de acero. Pero tampoco es fácil determinar si en aquel momento en su ciudad podía haber tenido contacto con todo ello. La exploración de las revistas o libros depositados en aquel año en el Associació d'Arquitectes de Catalunya no me ha dado ninguna pista en tal sentido.

Profundizando en el tema se hubiera enterado de que el primer rascacielos de Chicago, el Monadnock Building de 1889, con sus escasos $67 \mathrm{~m}$ de altura, era el edificio de similares características más alto en obra de fábrica y que sus paredes de carga de fachada habían necesitado más de 1,5 m de espesor. Sin duda, se hubiera preguntado: ¿Qué 


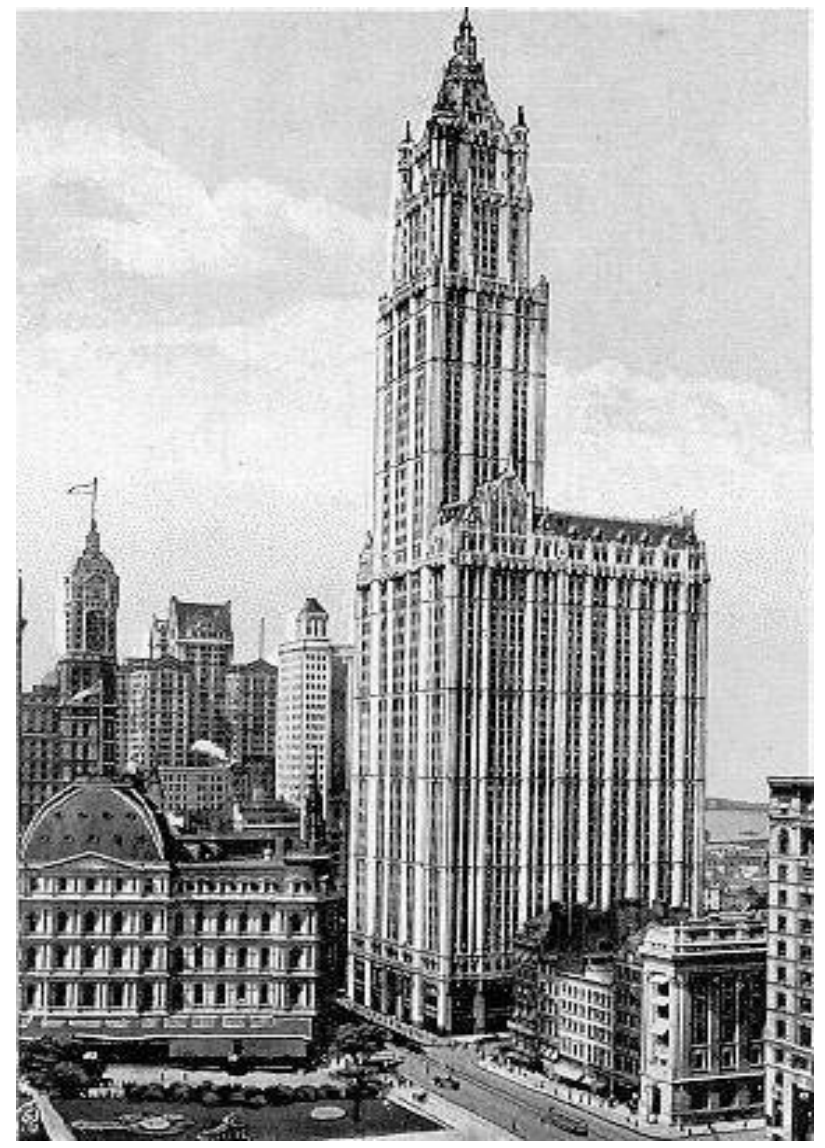

Figura 5.- El Woolworth Building iniciado en 1910 y acabado en 1913.

espesor deberá tener mi rascacielos, también de fábrica, de $360 \mathrm{~m}$ de altura? ¿qué dice al respecto la única formula disponible en la época, la de Rondelet? Nada, porque está pensada para edificios de dos o tres planta de altura. Y ¿entonces?

Gaudí, que demostró a lo largo se su vida ser muy inteligente, sin lugar a dudas, se hubiera dado cuenta de lo erróneo de su croquis inicial, basado en las torres de la Sagrada Familia, cuatro veces más bajas y huecas. Y, además, que en aquél momento, en aquella ciudad, no había tecnología, ni siquiera en estructura metálica, para llegar a esas alturas. Quizá llegó a saber que ya se estaba gestando, por parte de Mr. Woolworth y su arquitecto Cass Gilbert, el rascacielos de su nombre que superaría al Metropolitan con sus "escasos" 241 m (Fig. 5) y que pasaría a ser el más alto del mundo durante varias décadas y que, obviamente, se iba a construir con estructura de acero (Fig.6).

Cabe considerar la hipótesis de que, consciente de la falta de adecuación de la fábrica, hubiera adoptado la estructura metálica pero manteniendo el perfil catenárico (algo similar a lo que, en el siglo siguiente, hizo un arquitecto francés con hormigón armado escondido detrás de vidrios de colores, cuya forma justificó con referencias a Gaudí y ¡Montserrat!). En mi opinión, Gaudí no hubiera caído nun-

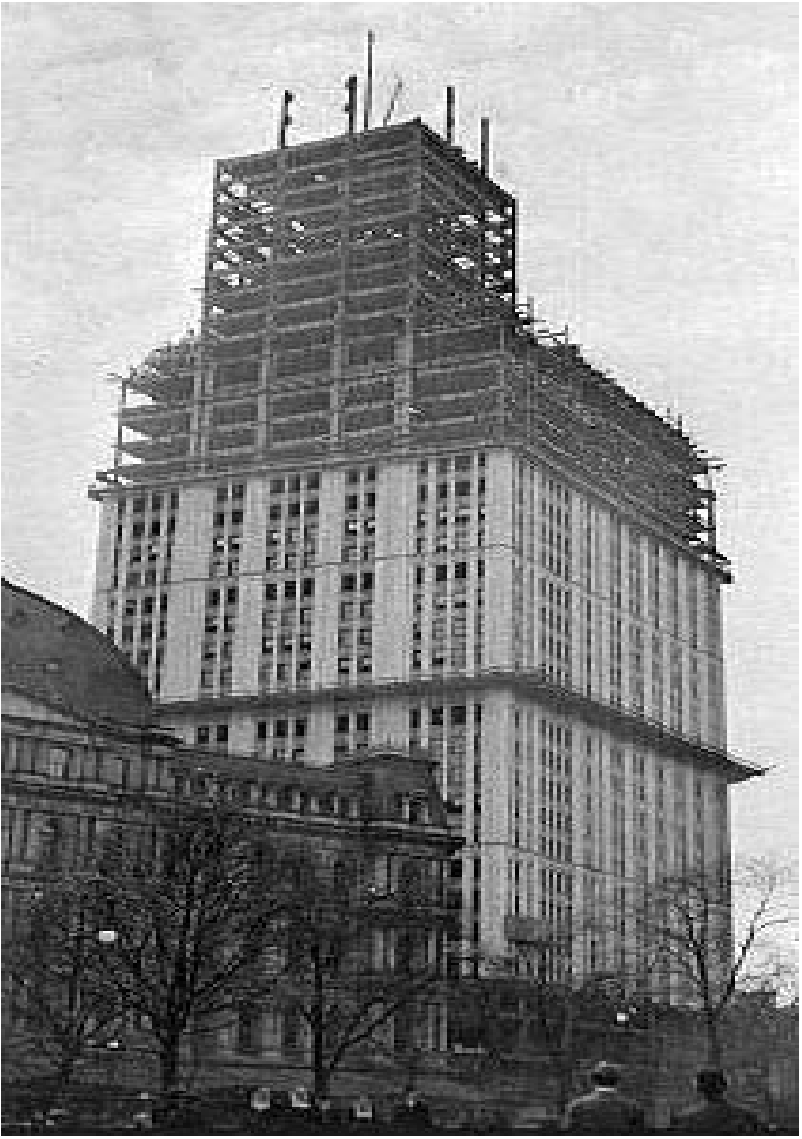

Figura 6.- Construcción del Woolworth con un entramado de perfiles de acero similar al del Flatiron.

ca tan bajo ya que mantuvo una fidelidad total en todas sus obras a la coherencia radical entre forma y material.

Probablemente, habría hecho un nuevo y portentoso proyecto sin ninguna referencia a la anticatenaria que yo no me considero capaz ni de atisbar, para eso él era Gaudí y yo no.

\section{VUELTA A LA REALIDAD}

Obviamente, esta ficción es totalmente improbable, no en si misma, sino porque no existe ningún documento que garantice que Gaudí recibiera dicho encargo y que si el croquis de la figura anterior lo llegó a dibujar él, lo fue de un edificio de, cómo máximo, unos $90 \mathrm{~m}$ de altura (las señales laterales indican, con toda probabilidad, alturas de $10 \mathrm{~m}$ ) que, en cualquier caso, hubiera tenido las mismas contradicciones en la relación material- forma antes indicadas. La hipótesis de los $360 \mathrm{~m}$ nos llevaría a dar por lógicas puertas de ¡18 m! de altura y ventanas de ¡9 m! Gaudí era exagerado, pero no loco.

Tal como ya expresé en ocasiones anteriores, en mi opinión, la idea del hotel de $360 \mathrm{~m}$ de obra de fábrica sólo fue consecuencia de la desbordante imaginación de un, supongamos bienintencionado, descendiente de personas 


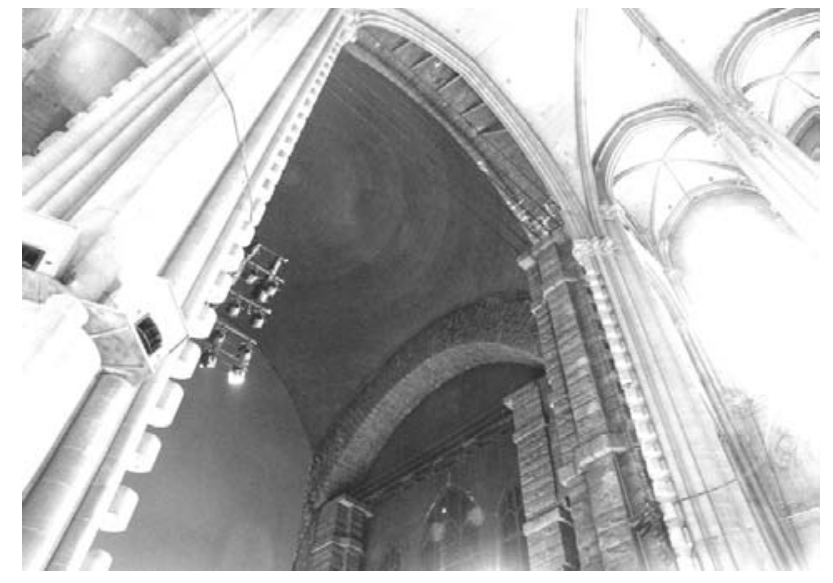

Figura 7.- Vista actual del crucero de la neoyorquina catedral de St. John the Divine. A pesar de la nula iluminación, se advierten las sucesivas hiladas circulares con las que se fue cerrando la cúpula.

próximas a Gaudí, y que sólo pudo pasar por su cabeza esa descomunal altura después de que se alcanzara realmente con el Empire State Building, obviamente, con estructura metálica.

Lo grave no es eso sino que todas las iniciativas oficiales del año Gaudí ya citadas anteriormente sólo sirvieron para convertir en "real" una inverosímil idea absurda acrecentando, una vez más, la confusión reinante sobre la obra de Gaudí basada en una desquiciada mitomanía. Fue una magnífica ocasión perdida para, con rigor, destacar las ya citadas y evidentes contradicciones e incrementar así la cultura sobre la materialización de la arquitectura histórica, no sólo del público en general, sino de muchos arquitectos que siguen sin entender la enorme diferencia que separa las estructuras del siglo XX con las de los siglos anteriores.

Y en esa línea de dar argumentos que faciliten la comprensión de algo tan lejano para muchos como la construcción histórica, creo interesante seguir con el hipotético, pero provechoso, viaje de Gaudí. Una vez cerrado el tema de los rascacielos, le hubiera sobrado tiempo hasta el viaje de vuelta, tiempo que habría aprovechado para seguir interesándose por la arquitectura y su construcción de una Nueva York en un proceso de crecimiento prodigioso.

\section{VUELTA A NUEVA YORK}

Y, sin duda, se habría interesado (quizá antes que por los rascacielos) por la obra de aquel maestro de obras valenciano, pero estudiante en Barcelona, que, en contra de la opinión de todos los arquitectos catalanes, había patentado en los EE. UU. algo tan esencial como la bóveda tabicada. ¿Cómo se llamaba? Sí hombre, Rafael,... Rafael Guastavino. ¿Y qué ha sido de él? Pues, mira, murió el año pasado y ahora es su hijo el que dirige la empresa que tiene la exclusiva de la construcción tabicada en Nortea- mérica. ¿Y qué tipo de obras hacen? El interlocutor le expuso una relación de las más importantes, la Biblioteca de Boston y acabó diciendo: una de las más recientes ha sido una cúpula rebajada en el crucero de la nueva catedral gótica de St. John the Divine.

Con toda probabilidad, Gaudí, que ya hacía muchos años que estaba deseando superar el gótico, se mostró interesado y consiguió una visita guiada de la mano de Rafael Guastavino, hijo.

No es fácil saber en qué idioma hablaron, ya que Rafael, de padre valenciano pero residente en tierras anglófonas desde hacia 28 años, cuando sólo tenía 9, difícilmente hablaría catalán. Pero de una manera u otra, le explicaría la asombrosa gesta técnico-empresarial que habían finalizado hacía pocos días, el 16 de agosto, con la que pudieron cubrir una luz de 29,9 x 29,9 m con una cúpula vaída tabicada situada entre 30 y $50 \mathrm{~m}$ de altura sin ningún tipo de cimbra y en sólo tres meses y dieciséis días, la mayor bóveda tabicada construida nunca (7) (Fig. 7). Nada de lo que se había hecho en Barcelona, ni él ni Domènech, ni Puig, (8) era comparable. Realmente, las posibilidades del sistema tabicado, tan catalán él, eran mucho mayores de lo que se estaba haciendo en Cataluña, al menos en lo dimensional.

Con todo, la estancia en la ciudad de los rascacielos y los Guastavinos finalizó y Gaudí volvió a estar en paro forzoso durante los días que necesitó para volver a Europa y Barcelona. Pero fue un paro relativo: previendo un ocio improductivo, había incluido en su equipaje diversos planos y croquis de las obras que estaba haciendo, aquéllos eran, básicamente, la iglesia de la Colonia Güell y la Sagrada Familia. Lo cual le permitió poner juntos los de su obra magna con los que Guastavino le había dado del edificio de San Juan, especialmente los del crucero. Gaudí los comparó (Figs. 8 y 9) Lo sospechado se volvió evidente: las dimensiones que salvaba la cúpula tabicada eran mucho mayores que las de las suyas.

Pero son casos no estrictamente comparables. Los empujes de la cúpula están perfectamente equilibrados por el robustísimo conjunto de arcos y pilares con los que el arquitecto Christopher G. La Farge ha organizado el crucero de Sant John. Sin embargo, mis arcos y mis cúpulas se autoequilibran. Sí, pero por eso no pueden cubrir grandes luces. A ver si tengo que cambiar todo, el rascacielos, la Sagrada Familia... Si lo llego a saber, no salgo de Barcelona...

Gaudí siguió discutiendo consigo mismo durante todo el trayecto sobre si lo de llegar hasta el final con la idea de suprimir contrafuertes y arbotantes era acertado y no era mejor sacar más partido a las bóvedas catalanas, situándolas entre estribos verticales, como siempre había sido; si sus luces eran ridículas comparadas con las de St. John; 

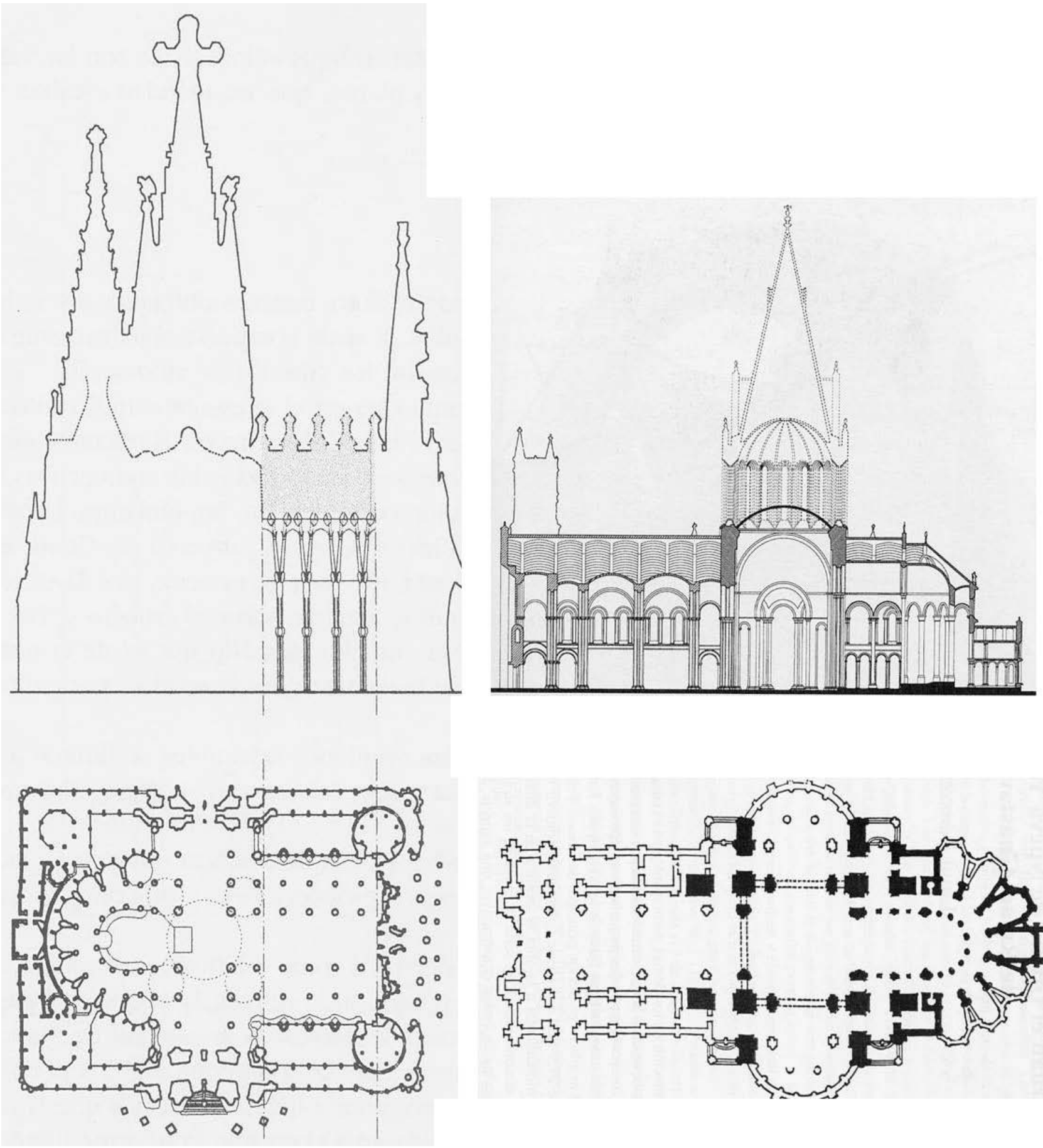

Figura 8.- El proyecto de la nueva catedral de Nueva York quedaba en su conjunto de menores dimensiones que la Sagrada Familia, aunque las luces de las naves eran mayores.

si lo del hotel estaba ciertamente equivocado, y si realmente, nunca llegaría a superar el gótico o, si de verdad, era necesario superar ni el gótico ni nada cuando los caminos de la arquitectura (Nueva York, a pesar de todas sus contradicciones, era el futuro) se dirigían hacia metas tan diferentes de las que se había propuesto cuando, con 31 años, había sustituido, no con muy buenas maneras (9), al arquitecto del Villar en la construcción de un templo neogótico.

\section{OTRA VEZ LA REALIDAD}

Pero, como ya sabe el lector, nada de eso ocurrió. Ni lo de Nueva York, ni lo del hotel, ni lo de la visita con Guastavino 

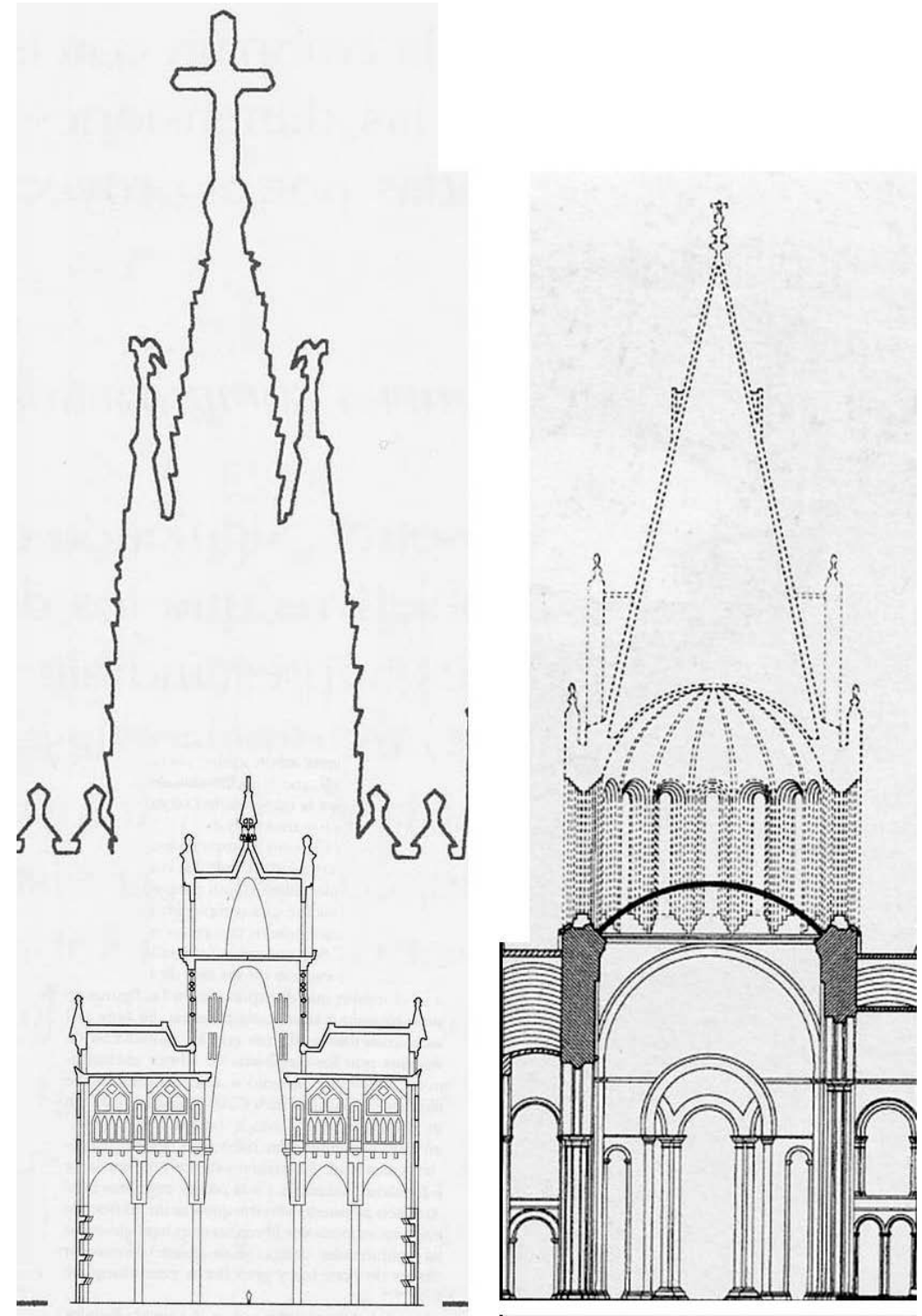

Figura 9.- En la sección se advierte la relativa menor dimensión de las naves gaudinianas; la comparación entre los cruceros acrecienta la diferencia.

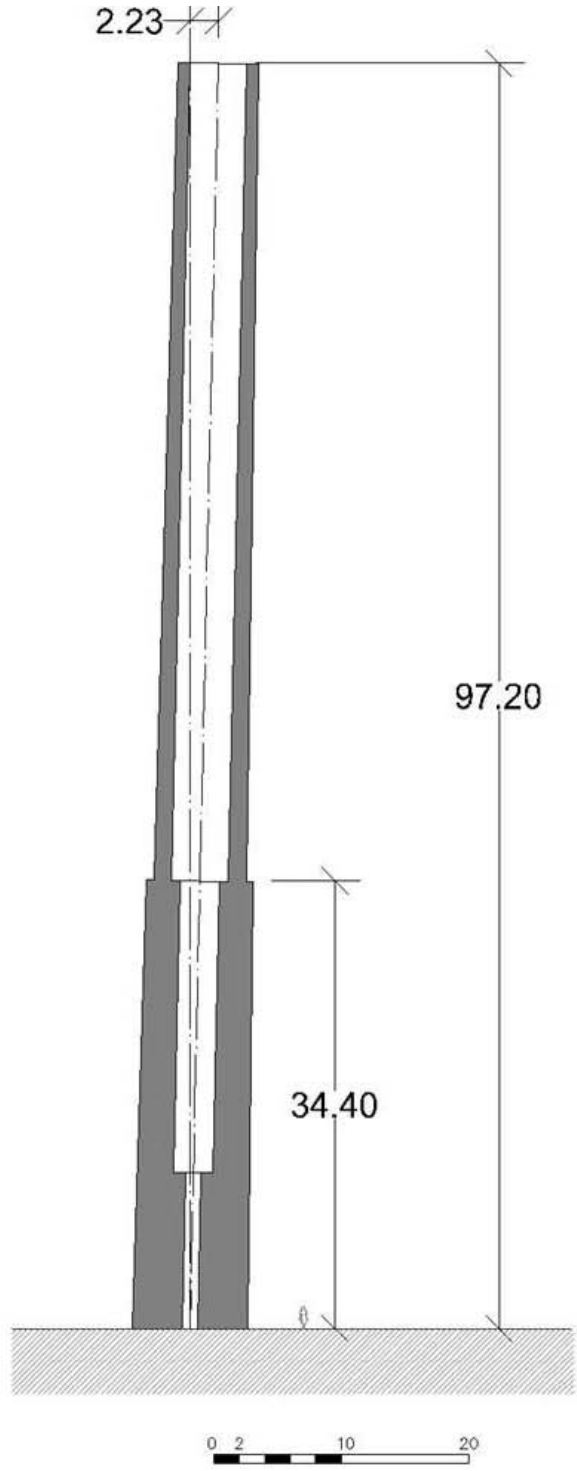

Figura 10.- Sección de la boloñesa torre Asinelli, telescópica e inclinada, pero incólume. hijo, ni lo de las dudas consiguientes sobre si debía superar al gótico, ni nada. Gaudí lo tuvo todo muy claro: él había superado el gótico haciendo sus torres no telescópicas y suprimiendo las muletas con las que se aguantaban los cuerpos defectuosos de las catedrales francesas. El que la telescópica torre Asinelli de Bolonia fuera tan alta y esbelta como las suyas, y encima esté inclinada (Fig. 10); el que las luces de la Sagrada Familia fueran bastantes 


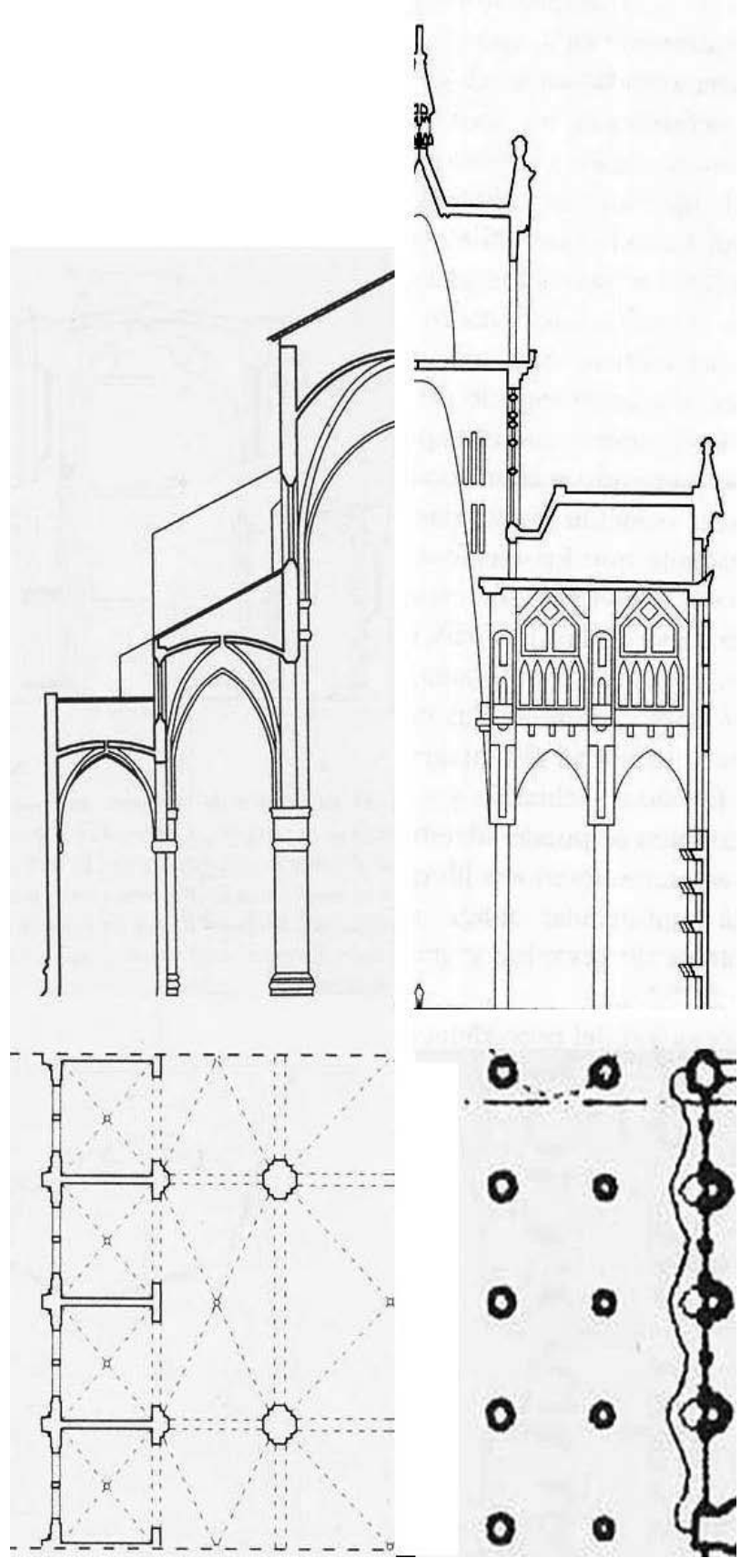

Figura 11.- Si seguimos en Bolonia, podemos comparar la Sagrada Familia con el descomunal San Petronio; las dos figuras 10 y 11 llevan a pensar en otro artículo: ¿y si Gaudi hubiera ido a Bolonia?

menores que las de la catedral de Gerona o que las de Mallorca y no digamos que las de S. Petronio de Bolonia (Fig. 11) o que necesitara construir otra catedral encima de la Sagrada Familia para conseguir verticalizar los reducidos empujes de sus pequeñas bóvedas (Fig. 12), fueron cuestiones de las que no fue consciente o no quiso serlo (10). En cualquier caso, en mi opinión, tenía derecho a decir y a hacer lo que quisiera de sí mismo y su obra. Sin embargo, también según mi opinión, la aceptación acrítica de todo lo que él dijo no parece ser una actitud propia de los profesionales de principios del siglo XXI.

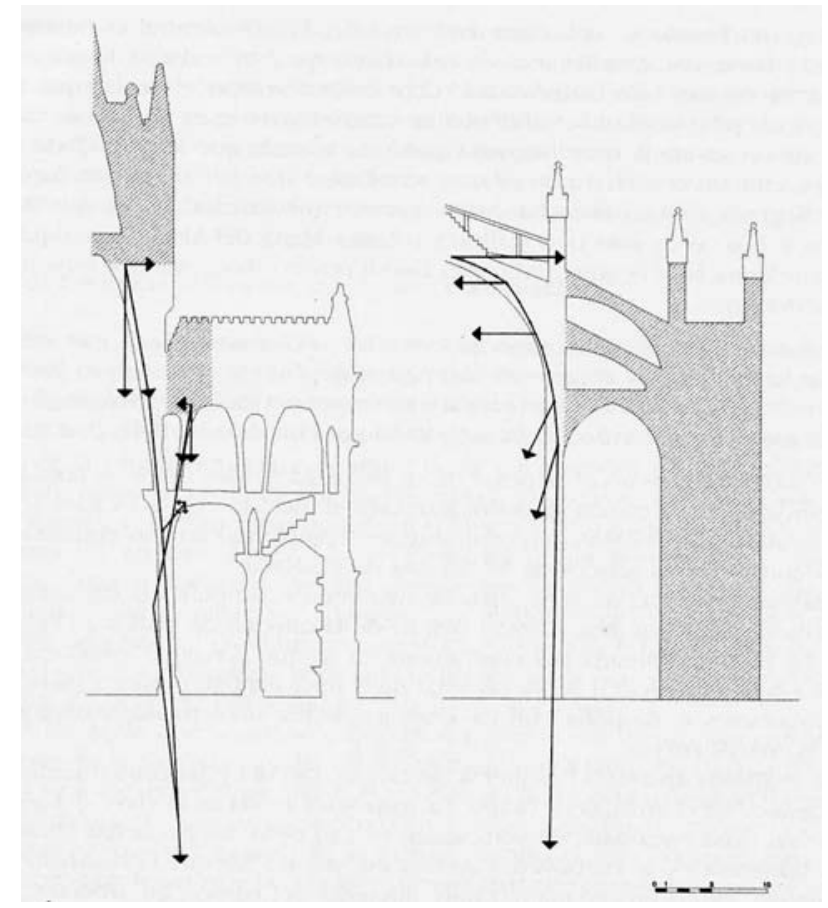

Figura 12.- Gaudi sitúa encima de las naves un cuerpo tan alto como la catedral de Barcelona para verticalizar los empujes de sus bóvedas, lo que también consigue la catedral de Mallorca con los contrafuertes, mucho más construibles.

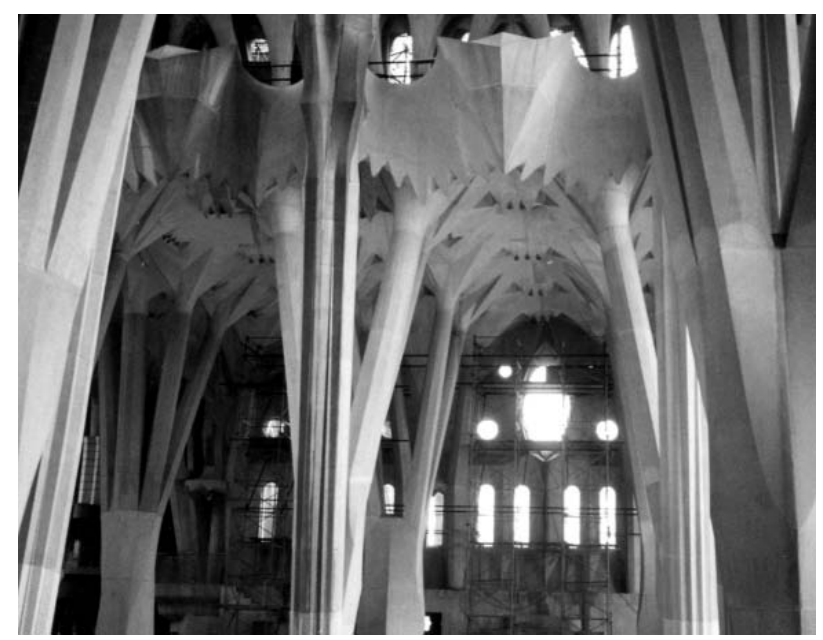

Figura 13.- Todo lo que se ve está realizado con hormigón armado.

Recuerdo muy bien cuando, con la máxima precaución, intentando no molestar su devoción por el maestro, le dije al director de las obras de la Sagrada Familia (11) que iba a publicar un libro en el demostraba que Gaudí no había superado el gótico; me miró asombrado, me cogió del brazo, me llevo a la nave y me señaló los puntales que, a modo de ramas de árboles, soportan las bóvedas de la cubierta, dijo "¡no ves que son más esbeltas que cualquier elemento gótico!" Mi respeto y admiración por el que ha asumido la pesada tarea de dirigir esas obras (que, con todas sus contradicciones, están dando forma real a uno 
de los legados más formidables de Gaudí, las complejas bóvedas de la nave) me contuvieron y no le contesté lo que tenía ganas: "ipero no ves que son de hormigón armado!'(Fig. 13).

Ahora bien, lo que es aceptable de un apasionado arquitecto implicado directamente en la obra póstuma de Gaudí, con quien le une un hilo casi directo, no lo es de los que ha asumido la responsabilidad de poner en práctica la actitud crítica propia de las instituciones universitarias. Muchos de ellos se sumaron a la vorágine del 2002 acrecentando una vez más la ya citada confusión reinante sobre la obra de Gaudí basada en una desquiciada mitomanía. Fue otra magnífica ocasión perdida para incrementar la cultura sobre la materialización de la arquitectura histórica (12).

Espero que ésta que doy por finalizada aquí sea una ocasión bien diferente.

\section{Notas}

(1) Bassegoda i Nonell, Joan, El Gran Gaudi, Sabadell, 1989. El autor de la memoria sobre el hotel es Joan Matamala.

(2) Josep M. Montaner, Pedro Azara , Joan Bassegoda ... [et al.] [editors:], Hotel Attraction : una catedral laica : el gratacel de Gaudi a New York, Barcelona, 2003

(3) J. L. González Moreno-Navarro, "Después del año Gaudí: ¿qué más sabemos de su obra?" Informes de la construcción. 481-482: 93-97, 2003
J. L. González Moreno-Navarro "Gaudí i l'hotel de Nova York", AVUI, 14 febrero 2003, p. 25

(4) Conferencia dictada el 19 de mayo de 2005 con el título "Innovación estructural en la arquitectura de Gaudí" dentro de los SEMINARIOS TORROJA, Tecnología de la Construcción y de sus Materiales, Ciclo $n^{\circ}$ 48: Primavera de 2005

(5) Jean Rondelet, L'art de bâtir, París 1802, 1818, láminas 23 y 43.

(6) J. L. González Moreno-Navarro y Albert Casals Balagué (2002), Gaudí y la razón constructiva. Un legado inagotable, Akal Ediciones, Madrid. Página 82.

(7) Luiggi Ramazzoti, "La cúpula para San Juan el Divino de Nueva York de Rafael Guastavino" en Las Bóvedas de Guastavino en América: libro publicado con ocasión de la exposición «Guastavino Co. (1885-1962): la reinvención de la bóveda, Madrid, 2001

(8) J. L. González Moreno-Navarro "La bóveda catalana en el final del siglo XIX: Guastavino, Domènech y Gaudí" de próxima publicación basado en la conferencia de igual título dictada en septiembre de 2003 dentro del Seminario sobre la arquitectura de la Corona de Aragón celebrado en Alguer (Cerdeña).

(9) J. L. González Moreno-Navarro y Albert Casals Balagué (2002), página 77 y 78 .

(10) Todo ello queda ampliamente tratado en José Luis González Moreno-Navarro y Albert Casals Balagué (2002), páginas 65108 , por lo que no se amplia más en este artículo.

(11) Jordi Bonet i Armengol, arquitecto

(12) En el ya citado artículo "Después del año Gaudí: ¿qué más sabemos de su obra?" Informes de la construcción. 481-482: 93-97, 2003, se hace una valoración del conjunto de aportaciones acaecidas el año Gaudí. 